\title{
Development and validation of a multiple-choice question-based delirium care knowledge quiz for critical care nurses
}

Short running title: Delirium care knowledge quiz

List of all authors: Mu-Hsing $\mathrm{Ho}^{\mathrm{a}, \mathrm{b}}$

a School of Nursing, University of Wollongong, New South Wales, Australia

b Department of Nursing, Taipei Medical University Hospital, Taipei, Taiwan

Corresponding author: Mu-Hsing HO RN, MSc

PhD candidate | University of Wollongong | Northfield Ave, NSW, 2522 Australia | School of

Nursing, Faculty of Science, Medicine and Health |E: $\underline{\text { mhh838@uowmaul.edu.au }}$

\section{Conflict of interest}

The authors have no conflicts of interest to declare.

\section{Funding Statement}

None. 


\title{
Development and validation of a multiple choice questions-based delirium care knowledge quiz for critical care nurses
}

\begin{abstract}
Aims: To develop and psychometrically test a multiple choice questions (MCQs)-based quiz of delirium care knowledge for critical care nurses.

Design: Instrument development and psychometric evaluation study.

Methods: The development and validation process including two phases. Phase I focused on the quiz development, conducted by the following steps: (1) generated initial 20-item pool; (2) examined content validity and (3) face validity; (4) conducted pilot testing, data were collected from 217 critical care nurses via online survey during 01 October to 07 November, 2020; (5) performed item analysis and eliminated items based on the item difficulty and discrimination indices. The MCQs quiz was finalised through the development process. Then, phases II emphasised the quiz validation, to estimate the internal consistency, split-half and test-retest reliability, and construct validity using parallel analysis with the exploratory factor analysis (EFA).
\end{abstract}

Results: A final 16-item MCQs quiz was emerged from the item analysis. The KuderRichardson Formula 20 coefficient for the overall quiz showed good internal consistency (0.85), and the intraclass correlation coefficient with a 30-day interval also indicated that the questionnaire had satisfactory stability (0.96). The EFA confirmed appropriate construct validity for the quiz, four factors could explain the total variance of $60.87 \%$.

Conclusion: This study developed the first MCQs quiz for delirium care knowledge and it is a reliable and valid tool that can be implemented to assess the level of delirium care knowledge.

Impact: This study offers an evidence-based quiz designed for future research and education purposes in delirium care that has significant implications for knowledge test by using MCQs in clinical practice.

Key words: Confusion; Critical care; Critical care nursing; Delirium; Evidence-based Practice; Intensive care; Knowledge; Multiple choice question; Nurses; Reliability and validity 
medRxiv preprint doi: https://doi.org/10.1101/2021.01.16.21249923; this version posted January 20, 2021. The copyright holder for this preprint (which was not certified by peer review) is the author/funder, who has granted medRxiv a license to display the preprint in perpetuity.

It is made available under a CC-BY-NC 4.0 International license .

\section{INTRODUCTION}

Delirium is the most common complication occurs among hospitalised patients, particularly in the intensive care unit (ICU). It is noted that delirium as a feature of COVID-19 may be increasingly found in critically ill patients who had severe infection and mechanically ventilated in ICU (British Geriatrics Society, European Delirium Association, \& Royal College of Psychiatrists, 2020). This updated guidance on delirium care also highlighted the importance of delirium prevention, early detection, assessment and management. According to the clinical practice guidelines for the prevention and management of Pain, Agitation/Sedation, Delirium, Immobility, and Sleep Disruption (PADIS) in adult patients in the ICU, evidence of delirium risk factors, prediction, and assessment were summarised for healthcare provider (Devlin et al., 2018). To understand the level of updated delirium care knowledge among critical care nurses is crucial as they are the frontline care providers in ICU. To date, several instruments investigating the delirium knowledge among ICU healthcare professionals were developed. However, only few instruments targeting critical care nurses as main population were comprehensively validated and evaluated (Elliott, 2014; Monfared, Soodmand, \& Ghasemzadeh, 2017; Öztürk Birge, Tel Aydın, \& Salman, 2020). Most developed instruments utilised options in true/false design to assess the knowledge of delirium. No existing instrument adopted the multiple choice questions (MCQs) quiz in measuring the level of delirium care knowledge was found. The MCQs is a strictly objective instrument that has been widely used in examinations and knowledge tests internationally (Gabriel \& Violato, 2009; Tweed, Purdie, \& Wilkinson, 2020). Little is known about whether a useful examination instrument such as MCQs quiz is reliable to assess knowledge of delirium care. Therefore, this study reported the development and validation process of a MCQs quiz in examining the knowledge of delirium care among critical care nurses. 
medRxiv preprint doi: https://doi.org/10.1101/2021.01.16.21249923; this version posted January 20, 2021. The copyright holder for this preprint (which was not certified by peer review) is the author/funder, who has granted medRxiv a license to display the preprint in perpetuity.

It is made available under a CC-BY-NC 4.0 International license .

\subsection{Background}

As noted, clinical guidelines have provided the summary evidence of delirium care in terms of understanding the predisposing and precipitating risk factors, delirium risk prediction model, validated assessment tool, the short- and long-term outcomes of delirium in critically ill adults and so on (Devlin et al., 2018). Aforementioned available delirium knowledge instruments have covered these topics such as diagnosis, risk factors, sign and symptoms, assessment as well as the health outcomes of delirium (Elliott, 2014; Öztürk Birge et al., 2020). A growing body of research has highlighted the utilisation of a delirium prediction model in detecting delirium risk in ICU (Cowan, Preller, \& Goudie, 2020; van den Boogaard et al., 2012; van den Boogaard et al., 2014). A recently meta-analysis also suggested that the delirium risk prediction model could be considered to applied in ICU settings (Ho, Chen, et al., 2020). Regarding the validated delirium assessment tools, a systematic review and diagnostic meta-analysis introduced several tools commonly used in ICU and indicated both the Confusion Assessment Method for the ICU (CAMICU) as well as the Intensive Care Delirium Screening Checklist (ICDSC) showed excellent sensitivity and specificity. Nevertheless, the CAM-ICU is recommended as the optimal tool due to its higher diagnostic test accuracy (Ho, Montgomery, et al., 2020). Considering to empower critical care nurses with sufficient level of delirium care knowledge and to be in line with the clinical guidelines (Department of Health and Ageing., 2011; Devlin et al., 2018; Scottish Intercollegiate Guidelines Network [SIGN], 2019), it is necessary to translate and implement latest evidence-based knowledge into clinical practice.

Given the rationale of employing a MCQs quiz in our study, several strategies to increase the quality of the MCQ can be considered in developing the quiz. For instance, 1) using the single best answer (SBA) which is the most common types of MCQs, so that the respondents would be 
familiar with the type and process of a test; 2) including allied distractors with correct answer which could increase the difficulty and discrimination of the questions; 3) adopting the use of "all/none of the above," options can potentially increase the item difficulty because it is harder to ascertain other options are correct or incorrect; 4) designing a brief introduction stem and a leadin question, respondents will be able to read and think the given stem to choose the most appropriate or likely option (Coughlin \& Featherstone, 2017; Schuwirth \& Van Der Vleuten, 2004). In order to develop a high quality MCQs quiz within the field of medical education, it is also essential to create questions with workplace simulated (i.e. a stem can be a clinical scenario description), problem solving and decision making descriptions, which can maximise the impacts and validity of the MCQ (Coughlin \& Featherstone, 2017; Maguire, Skakun, \& Triska, 1997; Naeem, van der Vleuten, \& Alfaris, 2012). Currently, there is no validated MCQs quiz for testing the delirium care knowledge among critical care nurses. Therefore, this study aimed to design a MCQs quiz to examine delirium care knowledge based on the existing clinical guidelines and published literature and evaluate its psychometric properties. The specific research question is 'whether the MCQs quiz is a reliable tool to assess delirium care knowledge among critical care nurses?'

\section{METHODS}

\subsection{Aims}

The purpose of the study was to develop and psychometrically test a MCQs-based delirium care knowledge quiz for critical care nurses. 


\subsection{Design}

This reliability and validity study described a two-phase process in development and validation of the delirium care knowledge quiz.

\subsection{Phase I: Development of the delirium care knowledge quiz}

The delirium care knowledge quiz was designed by the research team based on 1) the 'Delirium Care Pathways' which pre-dated the national standards for delirium care in Australia (Department of Health and Ageing., 2011); 2) the PADIS 2018 guideline of delirium care in ICU setting in USA (Devlin et al., 2018); 3) SIGH evidence-based guideline, a national clinical guideline in Scotland (SIGN, 2019); and 4) the existing evidence including systematic review and meta-analyses of delirium assessment and detection (Ho, Chen, et al., 2020; Ho, Montgomery, et al., 2020). To assess the level of delirium care knowledge in critical care nurses, a 20-item pool was generated by the research team (Table 1). The content of the preliminary version of the delirium care knowledge quiz including signs and symptoms, risk factors and aetiologies, assessment and detection of delirium care. The single-select, multiple choice question (MCQ) was considered as the most suitable form of the delirium care knowledge quiz. Furthermore, MCQs was used in a number of national and healthcare-related specialty board examinations (Coughlin \& Featherstone, 2017). Thus, our target respondents might not feel difficult to answer. In the initial quiz, most items $(n=14)$ were 4-option MCQs, some were 2-option $(n=4)$, and two questions were 5-option MCQs. A correct SBA was allocated 1 point while incorrect answer or missing response was scored 0 points, yielding the range of the quiz from 0 to 20 points from 20 initial items.

\subsubsection{Content validity}

The content of the quiz was examined by five experts consisted of an intensivist, two senior critical care nurses, a clinical nurse educator and a psychiatrist. The content agreement among experts in 
medRxiv preprint doi: https://doi.org/10.1101/2021.01.16.21249923; this version posted January 20, 2021. The copyright holder for this preprint (which was not certified by peer review) is the author/funder, who has granted medRxiv a license to display the preprint in perpetuity.

It is made available under a CC-BY-NC 4.0 International license .

four aspects including the content relevance, applicability, representativeness, and clarity were evaluated using a 5-point Likert scale ( 1 = very low to 5 = very high) on each item (Haynes, Richard, \& Kubany, 1995; Polit \& Beck, 2006). The values of Content Validity Index (CVI) for the content relevance, applicability, representativeness, and clarity were $80.6 \%, 80.4 \%, 83.0 \%$, and $87.6 \%$, respectively. The CVI of each item was $\geq 80 \%$, thus no question was eliminated and only one question was slightly amended in the wording for its presentation based on the comments from experts. The overall CVI calculated for the delirium care knowledge quiz was $82.9 \%$.

\subsubsection{Face validity}

Face validity refers to the appearance of an instrument (Considine, Botti, \& Thomas, 2005). To assess the face validity, clarity and readability of the delirium care knowledge quiz, the 20-item pilot quiz was administered to 15 volunteer nurses with at least one-year clinical experience in ICU. Considering the target population is critical care nurses, the volunteer nurses were purposive invited by primary investigator from ICUs at three university-affiliated hospitals. All nurses reported that the quiz was understandable, and no further change was required.

\subsubsection{Sample for pilot testing and psychometric properties}

Participants were recruited from three acute metropolitan teaching hospitals in northern Taiwan. Selection criteria were registered nurses who worked in ICU, and were older than 20 years. Critical care nurses who worked in the neonatal ICU or emergency room were excluded. The pilot quiz was distributed using a web-based survey tool (Qualtrics, Provo, UT) to gather information from the respondents. The online survey consisted of characteristics of respondents and the pilot quiz. Only basic characteristics information was collected including age, gender, ICU types (medical/surgical/mixed), and education level. The invitation with an electronic link with a QR code was sent to the department of nursing and the head nurses of ICUs. The title page of the 
medRxiv preprint doi: https://doi.org/10.1101/2021.01.16.21249923; this version posted January 20, 2021. The copyright holder for this preprint (which was not certified by peer review) is the author/funder, who has granted medRxiv a license to display the preprint in perpetuity.

It is made available under a CC-BY-NC 4.0 International license .

online survey provided information regarding the study aim, the use and storage of data. Participants were also fully informed that this was an anonymous survey and all collected data were de-identified. Completion of the survey was considered to imply consent. In order to conduct the factor analysis, the estimated sample size for a 20 -item test was 200 participants, which was based on the rule of 10 people per item (Goldberg \& Velicer, 2006). The quiz was piloted with 228 critical care nurses. Eleven observations were dropped by primary investigator due to the missing responses were more than $60 \%$ of the whole quiz. Finally, data from 217 critical care nurses were analysed. Data was collected during 01 October 2020 to 07 November 2020.

\subsubsection{Item analysis}

The item difficulty index $(P)$ was generated based on the correct response rate for each item (Ahmann \& Glock, 1981; Considine et al., 2005). It was used to describe the distribution of difficulty of a quiz. The ratio ranging from 0.00 to +1.00 was calculated by the number of the respondents with correct answer $(K)$ divided the total number of the respondents. If the ratio of an item approaches +1.00 that means the question is easy. It is recommended that items with an item difficulty index $<0.20$ and $>0.80$ which implied the question is extremely easy or difficult should be considered to remove (Ahmann \& Glock, 1981; Rush, Rankin, \& White, 2016).

The item discrimination index was used to evaluate the discriminating degree of a quiz between respondents answering an item correctly or incorrectly (Considine et al., 2005; Rush et al., 2016). The following steps were conducted to compute the item discrimination index for each item: 1) sorted the total scores of the quiz in an ascending order in the statistics software, and ranked the first respondent with lowest score as from one; 2) defined high-scoring group and lowscoring group. The common method was $27 \%-70 \%$ rule proposed by Kelly (1939), the first $27 \%$ of respondents with lower scores and $70 \%$ of respondents with higher scores (Kelley, 1939) were 
identified $(n=125)$. Thus, the 59 respondents ( $27 \%$ of 217 , ranked $1-59)$ were marked as the lowscoring group and 66 (70\% of 217, ranked 152-217) respondents were labelled as the high-scoring group; 3) calculated the correct response rate on each item in both high-scoring group $\left(P_{H}\right)$ and low-scoring group $\left(P_{L}\right)$; 4 ) performed an independent $t$ test to examine the difference in total scores between high-scoring group and low-scoring group in order to confirm the significant differences between groups exist; Finally, the value of the discrimination index $(D)$ for each item was computed according to the following formula:

$$
\text { Item discrimination index }(D)=P_{H}-P_{L}
$$

The index ranges from -1.00 to +1.00 , and items with the index $<0.25$ should be deleted (Ebel \& Frisbie, 1991). In this study, we removed items which suggested by item difficulty index and item discrimination index and finalised the delirium care knowledge quiz. The reliability test and psychometric evaluation were undertaken to examine the final quiz in the validation process.

\subsection{Phase II: Validation of the delirium care knowledge quiz}

\subsubsection{Internal consistency and test-retest reliability}

The quiz of delirium care knowledge was finalised after the reduction of question items by item analysis. The internal consistency was calculated using the Kuder-Richardson Formula 20 (KR20) coefficient to ensure the consistency of each item. Item-total correlations and correlated itemdeleted analyses were also conducted to examine the robustness of the item reliability. Moreover, the final quiz was divided to two parts by odds- and even ordered and the split-half coefficient was computed to demonstrate the overall consistency. The Cronbach's alpha or KR-20 coefficient which greater than 0.70 is considered as a reliable item/tool (Tavakol \& Dennick, 2011). 
The test-retest reliability reflects the variation in measurements taken by a tool on the same participants under the same conditions (Koo \& Li, 2016). The intraclass correlation coefficient (ICC) was used to report the test-retest reliability of the quiz. Fifteen critical care nurses who took the 20-item pool test and assessed the face validly were invited again to undertake the finalised quiz (16 items) after 30 days. The data was compared and adopted to calculated the ICC. The values of ICC between 0.5 and 0.75 indicate moderate, $0.75-0.9$ indicate good reliability, and values greater than 0.90 indicate excellent reliability (Portney \& Watkins, 2009).

\subsubsection{Construct validity}

For the contrast validity of the final quiz, firstly, the parallel analysis with a graphical scree plot approach was employed to determine the number of factors in this quiz. Then, the exploratory factor analysis (EFA) was applied to confirm the construct validity of the quiz. The Kaiser-Meyer-

Olkin (KMO) measure of sampling adequacy (using a cut-off of 0.5), and Barlett's Test of Sphericity $(p<.001)$ were employed to ensure the appropriateness of data set for EFA (Kaiser, 1974). The eigenvalues and factor loadings were evaluated for the construct validity of the quiz. In the EFA, item with factor loading $<0.4$ should be removed and re-modelling the structure of EFA (Hair, Black, Babin, \& Anderson, 2010). The average communalities value between 0.5 and 0.6 is considered as acceptable for sample size around 200 (MacCallum, Widaman, Preacher, \& Hong, 2001).

\subsection{Ethical and considerations}

Participants were voluntary and all data were anonymous and de-identified. The protocol of this cross-sectional pilot study was granted by a university Ethical Committee (Approval Number: N202009052). 
medRxiv preprint doi: https://doi.org/10.1101/2021.01.16.21249923; this version posted January 20, 2021. The copyright holder for this preprint (which was not certified by peer review) is the author/funder, who has granted medRxiv a license to display the preprint in perpetuity.

It is made available under a CC-BY-NC 4.0 International license.

\subsection{Data analysis}

The Statistical Package for Social Sciences (IBM SPSS Statistics for Windows, Version 25.0. Armonk, NY: IBM Corp.) was used to analysed the abovementioned data, reliability and validity tests. Frequency, percentage, mean, and standard deviation were used to present and distribution of variables in characteristics of nurses. All tests were two-tailed and the significance level $(\alpha)$ was set at 0.05 .

\section{RESULTS}

The characteristics of the participants are shown in Table 2. Most of the critical care nurses were female $(87.5 \%)$, worked in medical $(45.2 \%)$ or surgical $(44.7 \%)$ ICU, with an undergraduate degree $(93.1 \%)$. The mean age of nurses was 31.2 years $(S D=7.1), 57.9 \%(n=124)$ were aged 20 to 30 years, $30.8 \%(n=66)$ were $31-40$ years, and $11.2 \%(n=24)$ were over 40 years.

\subsection{Phase I: Finalise the quiz}

\subsubsection{Item analysis}

The independent $t$ test showed there was a significant difference in total scores between highscoring $(n=66)$ group and low-scoring $(n=59)$ group $(t=-25.908, p<.001)$ that supported an excellent discrimination of the quiz. The item difficulty index $(P)$ indicated item 1 and 10 were too easy and item 4 and 11 were too difficult in the quiz (out of the $0.20-0.80$ range), and all item discrimination indices $(D)$ for these four items were $<0.25$, which also demonstrated low discrimination of the questions (Table 3). Accordingly, item 1, 4, 10, 11 were removed from the quiz. Table 3 also presented the difficulty indices of the quiz ranging from 34.6 to 79.7 within the remained items. The discrimination indices in two items were greater than 0.40 which showed these questions were very good discriminator in the quiz. The final quiz with 16-item was 
medRxiv preprint doi: https://doi.org/10.1101/2021.01.16.21249923; this version posted January 20, 2021. The copyright holder for this preprint (which was not certified by peer review) is the author/funder, who has granted medRxiv a license to display the preprint in perpetuity.

It is made available under a CC-BY-NC 4.0 International license .

confirmed and finalised. The mean score of the delirium care knowledge quiz on the 16-item MCQs was $10.3(\mathrm{SD}=4.0)$ with a range 1-16.

\subsection{Phase II: Evaluate the reliability and validity of the final quiz}

\subsubsection{Internal consistency and test-retest reliability}

The total quiz had an internal consistency of 0.854 (KR-20) which indicated the final quiz is a reliable test. The Spearman-Brown coefficient of 0.767 for split-half reliability also confirmed the reliability of the final quiz. The item-total correlations revealed that all items were correlated with the total score of the quiz significantly $(p<0.0001)$. The results of correlated item-total correlation and the Cronbach's alpha if item deleted were summarised in Supplementary Table 2. The ICC of 0.961 (95\% CI: .903-.989, $p<0.0001)$ highlighted an excellent test-retest reliability of the quiz.

\subsubsection{Construct validity}

In Figure 1, four factor components were determined by the parallel analysis as the eigenvalue of the fifth factor was less than 1.0 in the graphical scree plot. The EFA using principal component analysis with varimax rotation was performed. The KMO of $0.823(>0.5)$ and the Barlett's Test of Sphericity $(p<0.0001)$ suggested the collected data was appropriate to conduct EFA. In the EFA, the eigenvalue of four factors could explain the total variance of $60.87 \%$. All factor loadings of items were $>0.439$ or above. The average communality value was 0.653 , and in each item was $>0.4$, indicating each item shares some common variance for all 16 items (Table 4).

\section{DISCUSSION}

This study aimed at developing and psychometrically testing the 16-item MCQs quiz of the delirium care knowledge. The results have demonstrated our MCQs quiz is a reliable and validated tool to assess delirium care knowledge among critical care nurses. Among all items in the quiz, 
one difficult item with good discrimination degree is about interpreting the result of CAM-ICU assessment (item 18). Surprisingly, this item had only $34.6 \%$ correct response rate from critical care nurses, which highlighted an urgent need to educate and improve their knowledge of using CAM-ICU. A possible explanation is that participants are more familiar with other delirium assessment tools such as ICDSC or 4AT in their daily practice. Still, critical care nurses should be able to recognise the correct answer because the CAM-ICU had been introduced and suggested to be used in the Taiwan Clinical Practice Guidelines for the Management of Pain, Agitation, and Delirium in Adult Intensive Care Unit (Taiwan PAD) since 2016 (Tay, Chan, Chen, Chou, \& Huang, 2016). Consistent with findings from previous study conducted in the UK, education on ICU delirium is warranted in particular the training in delirium screening (Elliott, 2014). Thus, there is a growing demand for implementing education interventions and programs to improve critical care nurses' knowledge in CAM-ICU assessment.

The fundamental content of the items including signs and symptoms, risk factors of delirium are important and similar items could be also found in previous tools in assessing delirium knowledge (Elliott, 2014; Öztürk Birge et al., 2020). However, our findings indicated that these items testing basic knowledge (item $8,13,15,16$ ) seem to be too easy (item difficulty index $>70 \%$ ). These results are line with previous study using a validated tool (Öztürk Birge et al., 2020). Although these items were not removed, future studies may consider revising the options and adding distractors to ensure the concept of the knowledge is measured, and reduce the chance of correct response rate by guessing. For example, using either 'None of the above' or 'All of the above' rather than using both in a single question which might prompt the correct answer to respondents (Rush et al., 2016). 
medRxiv preprint doi: https://doi.org/10.1101/2021.01.16.21249923; this version posted January 20, 2021. The copyright holder for this preprint (which was not certified by peer review) is the author/funder, who has granted medRxiv a license to display the preprint in perpetuity.

It is made available under a CC-BY-NC 4.0 International license .

Our findings also discovered that items with stem and lead-in questions work well in terms of the response rate and item difficulty. None of missing responses were received from these four items and the difficulty were considered acceptable (item difficulty index between 34.6-61.8\%). In our quiz, we did not design a case report-like stem in our item (i.e. An 83-year-old woman presented with confusion...) due to the consideration in length of the quiz while it is recommended to be included (Considine et al., 2005; Coughlin \& Featherstone, 2017; Naeem et al., 2012). This is an interesting topic for future studies to discover how the MCQs with clinical scenario description can extend the knowledge measurement beyond testing simple concept of knowledge.

Understanding the sufficient level of knowledge depends on a reliable and valid tool. The findings indicated that this MCQs quiz has appropriate psychometric properties. Although this quiz was developed for and validated in critical care nurses, we recommended that this quiz could be also used in undergraduate curricula as an examination quiz and assessment task in critical care nursing related subjects. The reason for adopting this quiz is because components were developed according to clinical guidelines which provided the practical guidance that should be integrated into the learning objectives. Central to the learning outcomes in delirium care among critical care nurses or nursing students is the clinical practice driven by the knowledge acquisition.

\subsection{Limitations}

This study had several strengths such as developing the first validated MCQs quiz that can be used in both undergraduate curricula and continuing medical/nursing education, reporting the estimates of reliability and validity comprehensively, and adopting strategies to create high quality MCQs and using item analysis to test the question difficulty and discrimination. Nevertheless, some limitations were noted in this study. First, in this self-developed instrument, we did not have theoretical perspectives to support the development of the quiz. In order to design a knowledge- 
based assessment instrument, we used more than one clinical practice guidelines and the latest evidence-based literature to create initial items. The concept of delirium care knowledge was included in our quiz, and the multidimensional psychometric properties were carefully estimated in the validation process. Second, the generalisability/external validity of the results might be limited due to the all participants were recruited from a single area, northern Taiwan. Lastly, the self-report online survey method might cause the social-desirability bias, for example, respondents can search the correct answer before response to the online survey. Despite these limitations, the quiz had the optimal statistical properties with regard to measuring the level of delirium care knowledge among critical care nurses.

\section{CONCLUSION}

Understanding the level of delirium care knowledge among critical care nurses is vital to support future education interventions in ICU settings. The MCQs quiz developed in this study is a reliable and valid tool that can be implemented to assess the level of delirium care knowledge. It is an evidence-based quiz designed for future research and education purposes in delirium care that has significant implications for knowledge test by using MCQs in clinical practice.

\section{Conflict of Interest statement}

No conflict of interest has been declared by the authors. 
medRxiv preprint doi: https://doi.org/10.1101/2021.01.16.21249923; this version posted January 20, 2021. The copyright holder for this preprint (which was not certified by peer review) is the author/funder, who has granted medRxiv a license to display the preprint in perpetuity.

It is made available under a CC-BY-NC 4.0 International license .

\section{References}

Ahmann, J. S., \& Glock, M. D. (1981). Evaluating student progress : principles of tests and measurements (6th ed. ed.). Boston: Allyn and Bacon.

British Geriatrics Society, European Delirium Association, \& Royal College of Psychiatrists. (2020). Coronavirus: Managing delirium in confirmed and suspected cases. Retrieved from https://www.bgs.org.uk/sites/default/files/content/attachment/2020-0326/BGS\%20Coronavirus\%20-\%20Managing\%20delirium\%20in\%20confirmed\%20and\% 20suspected\%20cases_0.pdf

Considine, Julie, Botti, Mari, \& Thomas, Shane. (2005). Design, format, validity and reliability of multiple choice questions for use in nursing research and education. Collegian, 12(1), 1924. doi:10.1016/S1322-7696(08)60478-3

Coughlin, P. A., \& Featherstone, C. R. (2017). How to Write a High Quality Multiple Choice Question (MCQ): A Guide for Clinicians. European Journal of Vascular and Endovascular Surgery, 54(5), 654-658. doi:10.1016/j.ejvs.2017.07.012

Cowan, S. L., Preller, J., \& Goudie, R. J. B. (2020). Evaluation of the E-PRE-DELIRIC prediction model for ICU delirium: a retrospective validation in a UK general ICU. Critical Care, 24(1), 123. doi:10.1186/s13054-020-2838-2

Department of Health and Ageing. (2011). Dlirium Clinical Pathway. Retrieved from https://www1.health.gov.au/internet/main/publishing.nsf/Content/Delirium-CarePathways

Devlin, J. W., Skrobik, Y., Gelinas, C., Needham, D. M., Slooter, A. J. C., Pandharipande, P. P., .. . Alhazzani, W. (2018). Clinical Practice Guidelines for the Prevention and Management of Pain, Agitation/Sedation, Delirium, Immobility, and Sleep Disruption in Adult Patients in the ICU. Critical Care Medicine, 46(9), e825-e873. doi:10.1097/ccm.0000000000003299 
medRxiv preprint doi: https://doi.org/10.1101/2021.01.16.21249923; this version posted January 20, 2021. The copyright holder for this preprint (which was not certified by peer review) is the author/funder, who has granted medRxiv a license to display the preprint in perpetuity.

It is made available under a CC-BY-NC 4.0 International license .

Ebel, R. L., \& Frisbie, D. A. (1991). Essentials of Educational Measurement (5th ed ed.). Englewood Cliffs.: Prentice-Hall.

Elliott, S. R. (2014). ICU delirium: a survey into nursing and medical staff knowledge of current practices and perceived barriers towards ICU delirium in the intensive care unit. Intensive and Critical Care Nursing, 30(6), 333-338. doi:10.1016/j.iccn.2014.06.004

Gabriel, A., \& Violato, C. (2009). The development of a knowledge test of depression and its treatment for patients suffering from non-psychotic depression: a psychometric assessment. BMC Psychiatry, 9, 56. doi:10.1186/1471-244x-9-56

Goldberg, Lewis R., \& Velicer, Wayne F. (2006). Principles of Exploratory Factor Analysis. In Differentiating normal and abnormal personality, 2nd ed. (pp. 209-237). New York, NY, US: Springer Publishing Company.

Hair, J. F., Black, W. C., Babin, B. J., \& Anderson, R. E. (2010). Multivariate data analysis: International version. New Jersey, NJ, US: Pearson.

Haynes, Stephen N., Richard, David C. S., \& Kubany, Edward S. (1995). Content validity in psychological assessment: A functional approach to concepts and methods. Psychological Assessment, 7(3), 238-247. doi:10.1037/1040-3590.7.3.238

Ho, M. H., Chen, K. H., Montayre, J., Liu, M. F., Chang, C. C., Traynor, V., . . Chiu, H. Y. (2020). Diagnostic test accuracy meta-analysis of PRE-DELIRIC (PREdiction of DELIRium in ICu patients): A delirium prediction model in intensive care practice. Intensive and Critical Care Nursing, 57, 102784. doi:10.1016/j.iccn.2019.102784

Ho, M. H., Montgomery, A., Traynor, V., Chang, C. C., Kuo, K. N., Chang, H. R., \& Chen, K. H. (2020). Diagnostic Performance of Delirium Assessment Tools in Critically Ill Patients: A 
Systematic Review and Meta-Analysis. Worldviews on Evidence-Based Nursing, 17(4), 301-310. doi:10.1111/wvn.12462

Kaiser, Henry F. (1974). An index of factorial simplicity. Psychometrika, 39(1), 31-36. doi:10.1007/BF02291575

Kelley, T. L. (1939). The selection of upper and lower groups for the validation of test items. Journal of Educational Psychology, 30(1), 17-24. doi:10.1037/h0057123

Koo, T. K., \& Li, M. Y. (2016). A Guideline of Selecting and Reporting Intraclass Correlation Coefficients for Reliability Research. Journal of Chiropractic Medicine, 15(2), 155-163. doi:10.1016/j.jcm.2016.02.012

MacCallum, R. C., Widaman, K. F., Preacher, K. J., \& Hong, S. (2001). Sample Size in Factor Analysis: The Role of Model Error. Multivariate Behavioral Research, 36(4), 611-637. doi:10.1207/s15327906mbr3604_06

Maguire, TO, Skakun, EN, \& Triska, OH. (1997). Student Thought Processes Evoked by Multiple Choice and Constructed Response Items. In Advances in Medical Education (pp. 618-621): Springer.

Monfared, A., Soodmand, M., \& Ghasemzadeh, G. (2017). Knowledge and Attitude of Intensive Care Unit Nurses Towards Delirium Working at Guilan University of Medical Sciences in 2015. Preventive Care in Nursing \& Midwifery Journal, 7(1), 1-7.

Naeem, N., van der Vleuten, C., \& Alfaris, E. A. (2012). Faculty development on item writing substantially improves item quality. Advances in Health Sciences Education, 17(3), 369376. doi:10.1007/s10459-011-9315-2 
medRxiv preprint doi: https://doi.org/10.1101/2021.01.16.21249923; this version posted January 20, 2021. The copyright holder for this preprint (which was not certified by peer review) is the author/funder, who has granted medRxiv a license to display the preprint in perpetuity. It is made available under a CC-BY-NC 4.0 International license .

Öztürk Birge, A., Tel Aydın, H., \& Salman, F. (2020). The development of a delirium knowledge test for intensive care nurses: A validity and reliability study. Intensive and Critical Care Nursing, 102900. doi:10.1016/j.iccn.2020.102900

Polit, D. F., \& Beck, C. T. (2006). The content validity index: Are you sure you know what's being reported? Critique and recommendations. Research in Nursing \& Health, 29(5), 489-497. doi: 10.1002/nur.20147

Portney, Leslie Gross, \& Watkins, Mary P. (2009). Foundations of clinical research: applications to practice (Vol. 892): Upper Saddle River, NJ: Pearson/Prentice Hall.

Rush, Bonnie R., Rankin, David C., \& White, Brad J. (2016). The impact of item-writing flaws and item complexity on examination item difficulty and discrimination value. $B M C$ Medical Education, 16(1), 250. doi:10.1186/s12909-016-0773-3

Schuwirth, Lambert W T, \& Van Der Vleuten, Cees P M. (2004). Different written assessment methods: what can be said about their strengths and weaknesses? Medical Education, 38(9), 974-979. doi:10.1111/j.1365-2929.2004.01916.x

Scottish Intercollegiate Guidelines Network (SIGN). (2019). Risk reduction and management of delirium. Retrieved from https://www.sign.ac.uk/media/1423/sign157.pdf

Tavakol, M., \& Dennick, R. (2011). Making sense of Cronbach's alpha. International Journal of Medical Education, 2, 53-55. doi:10.5116/ijme.4dfb.8dfd

Tay, H. Z., Chan, K. S., Chen, C. M. , Chou, W., \& Huang, H. M. (2016). Taiwan Clinical Practice Guidelines for the Management of Pain, Agitation, and Delirium in Adult Intensive Care Unit (Taiwan PAD) Part IV: Strategies for clinical implementation and quality management. Resuscitation \& Intensive Care Medicine, 1, 90-99. 
Tweed, M., Purdie, G., \& Wilkinson, T. (2020). Defining and tracking medical student selfmonitoring using multiple-choice question item certainty. BMC Medical Education, 20(1), 344. doi:10.1186/s12909-020-02250-x

van den Boogaard, M., Pickkers, P., Slooter, A. J., Kuiper, M. A., Spronk, P. E., van der Voort, P. H., . . . Schoonhoven, L. (2012). Development and validation of PRE-DELIRIC (PREdiction of DELIRium in ICu patients) delirium prediction model for intensive care patients: observational multicentre study. $B M J, 344$, e420. doi:10.1136/bmj.e420

van den Boogaard, M., Schoonhoven, L., Maseda, E., Plowright, C., Jones, C., Luetz, A., . . . Pickkers, P. (2014). Recalibration of the delirium prediction model for ICU patients (PREDELIRIC): a multinational observational study. Intensive Care Medicine, 40(3), 361-369. doi:10.1007/s00134-013-3202-7 
Table 1. 20-item pool of the initial delirium care knowledge quiz

\begin{tabular}{l} 
Item NO./Answer and distractors \\
\hline Please select only ONE best or likely answer for each question:
\end{tabular}

1. Another term for acute confusion is ....

Notes

4-option

Organic confusion

Dementia

Delirium

Alzheimer's Disease

2. Delirium develops ....

4-option

Suddenly, over hours to days

Moderately, lasting for months

Slowly and insidiously over months

In line with the ageing process

3. Key signs and symptoms of delirium in hospitalised patients include:

4-option

Loss of long term memory and cognition

Wandering and antisocial behaviour

$\square$ Sudden changes in level of alertness and orientation

$\square$ Gradual disorientation to surroundings

4. The incidence of delirium in hospitalised patients is estimated at ....

4-option

$1 \%$

$15 \%$

$50 \%$

$80 \%$

5. The age group most at risk of developing delirium is ....

4-option

$\square$ Children under 12 years

Adolescents 13-18 years

Adults $19-59$ years

The older person $>65$ years

6. Which of the following group of patients is at greatest risk of developing

4-option delirium?

82-year-old man with a pre-existing diagnosis of dementia

50-year-old with Type 2 diabetes, hypercholesterolemia and obesity

20-year-old athletic, fit, student nurse

$\square$ 60-year-old man with central obesity

7. Which of the following patients may develop delirium?

5-option

$\square$ A person undergoing alcohol withdrawal and detoxification

A paediatric patient who is febrile

$\square$ A person with dementia admitted to hospital for 'unexplained weight loss"

None of the above

All of the above 
8. Delirium is caused by ....

4-option

A complex interaction of multiple factors

The normal aging process

Plaque like deposits in the brain

Ischemic attacks on the brain

9. If identified early enough and appropriate measures are taken, then the signs and

2-option symptoms of delirium

Yes, usually can be reversed

$\square$ No, it is not reversible

10. Delirium in an older person can lead to dementia

$\square$ True

False

11. Which of the following statements is true of delirium?

4-option

$\square$ It is inevitable in the elderly hospitalised patient

$\square$ It is a minor concern in the older patient

$\square$ It will resolve without the need for intervention

$\square$ It is a serious medical emergency

12. Which sub-type of delirium presents with lethargy and reduced motor

4-option behaviours?

$\square$ Hypoactive type

Hyperactive type

Dementia

$\square$ Sundowners

13. Which of the following place the older patient at greater risk of developing

4-option delirium?

Multiple aetiology

Use of multiple medications

Alterations in sensory acuity

All of the above

14. Delirium can worsen the functional state of patients with dementia?

2-option

$\square$ True

(True/False)

False

15. Which of the following predisposing factors are linked to delirium?

5-option

Age $>65$ and sensory impairment

Dehydration and dementia

Substance use (including alcohol) and chronic illness

None of the above

All of the above 
16. Precipitating factors for delirium include which of the following?

4-option

Infection and severe acute illness

Changes to electrolytes and oxygenation

Surgery and invasive procedures, such as urinary catheterisation

All of the above

[Stem for Item $17 \&$ 18]

The Confusion Assessment Method for the ICU (CAM-ICU) is a short delirium assessment tool that can be rapidly administered. The CAM-ICU consists of 4 key features including a RASS (Richmond Agitation-Sedation Scale) assessment to perform. It is recommended that critically ill patients should be regularly assessed for delirium using a valid tool like CAM-ICU.

17. Which of the following features is NOT included in CAM-ICU?

Lead-in

Acute change or fluctuating course of mental status

question;

Acute memory loss

4-option

Inattention

Disorganised Thinking

18. Delirium positively presented if one of the four features is positive in the CAMICU assessment.

Lead-in

$\square$ True

question;

False

2-option

(True/False)

[Stem for Item $19 \& 20]$

The PRE-DELIRIC (PREdiction of DELIRium in ICu patients) delirium prediction model allows for early prediction of delirium and it has been utilised in clinical ICU setting. The model consists of 10 predictors that are readily available within 24 hours after ICU admission. The predictive result presenting in percentage (\%) can be divided into low, moderate, high and very high risk. It is suggested that patients with a moderate risk of developing delirium should be closely monitored and assessed by a valid assessment tool at least once per shift.

19. Which of the following factors are NOT the predictors of PRE-DELIRIC?

Lead-in

SOFA (Sequential Organ Failure Assessment) score question;

24 h morphine use

4-option

Urea concentration

Metabolic acidosis

20. The PRE-DELIRIC model shows $26 \%$, which means the probability of patient to develop delirium need to be considered as....

Lead-in

Low risk group question;

Moderate risk group

4-option

High risk group

Very high risk group 
medRxiv preprint doi: https://doi.org/10.1101/2021.01.16.21249923; this version posted January 20, 2021. The copyright holder for this preprint (which was not certified by peer review) is the author/funder, who has granted medRxiv a license to display the preprint in perpetuity. It is made available under a CC-BY-NC 4.0 International license.

Table 2. Characteristics of participants in pilot testing $(N=217)$

\begin{tabular}{ccc}
\hline Characteristics & Mean (SD), range & $\mathrm{n}(\%)$ \\
\hline Age, years $(\mathrm{n}=190)$ & $31.2(7.1), 21-58$ & \\
$20-30$ & & $124(57.9)$ \\
$31-40$ & $66(30.8)$ \\
$40+$ & $24(11.2)$
\end{tabular}

Gender

Female $(\mathrm{n}=216)$

$189(87.5)$

Male

Type of ICU

Medical

98 (45.2)

Surgical

97 (44.7)

Mixed

$22(10.1)$

Education level

Undergraduate

$202(93.1)$

Postgraduate

$15(6.9)$

Note. $\mathrm{SD}=$ standard deviation; $\mathrm{ICU}=$ intensive care unit. 
Table 3. Results of item analysis on pilot quiz $(N=217)$

\begin{tabular}{|c|c|c|c|c|c|c|}
\hline 20-item pool & $K$ & $P$ & $P_{H}(\mathrm{n}=66)$ & $P_{L}(\mathrm{n}=59)$ & $D$ & Item remaining \\
\hline 1 & 193 & 88.9 & 0.512 & 0.344 & 0.168 & Removed \\
\hline 2 & 170 & 78.3 & 0.488 & 0.176 & 0.312 & $\checkmark$ \\
\hline 3 & 123 & 56.7 & 0.512 & 0.104 & 0.408 & $\checkmark$ \\
\hline 4 & 42 & 19.4 & 0.168 & 0.040 & 0.128 & Removed \\
\hline 5 & 167 & 77.0 & 0.520 & 0.176 & 0.344 & $\checkmark$ \\
\hline 6 & 166 & 76.5 & 0.496 & 0.176 & 0.320 & $\checkmark$ \\
\hline 7 & 143 & 65.9 & 0.528 & 0.112 & 0.416 & $\checkmark$ \\
\hline 8 & 173 & 79.7 & 0.520 & 0.216 & 0.304 & $\checkmark$ \\
\hline 9 & 168 & 77.4 & 0.520 & 0.224 & 0.296 & $\checkmark$ \\
\hline 10 & 204 & 94.0 & 0.512 & 0.416 & 0.096 & Removed \\
\hline 11 & 40 & 18.4 & 0.144 & 0.032 & 0.112 & Removed \\
\hline 12 & 154 & 71.0 & 0.528 & 0.152 & 0.376 & $\checkmark$ \\
\hline 13 & 162 & 74.7 & 0.512 & 0.136 & 0.376 & $\checkmark$ \\
\hline 14 & 62 & 28.6 & 0.312 & 0.008 & 0.304 & $\checkmark$ \\
\hline 15 & 172 & 79.3 & 0.528 & 0.256 & 0.272 & $\checkmark$ \\
\hline 16 & 171 & 78.8 & 0.528 & 0.248 & 0.280 & $\checkmark$ \\
\hline 17 & 97 & 44.7 & 0.360 & 0.048 & 0.312 & $\checkmark$ \\
\hline 18 & 75 & 34.6 & 0.368 & 0.016 & 0.352 & $\checkmark$ \\
\hline 19 & 91 & 41.9 & 0.360 & 0.080 & 0.280 & $\checkmark$ \\
\hline 20 & 134 & 61.8 & 0.488 & 0.136 & 0.352 & $\checkmark$ \\
\hline
\end{tabular}

Note. $K=$ number of correct response; $P=$ item difficulty index; $P_{H}=$ correct response rate in high-scoring group; $P_{L}=$ correct response rate in low-scoring group; $D=$ item discrimination index. 
medRxiv preprint doi: https://doi.org/10.1101/2021.01.16.21249923; this version posted January 20, 2021. The copyright holder for this preprint (which was not certified by peer review) is the author/funder, who has granted medRxiv a license to display the preprint in perpetuity.

$$
\text { It is made available under a CC-BY-NC } 4.0 \text { International license. }
$$

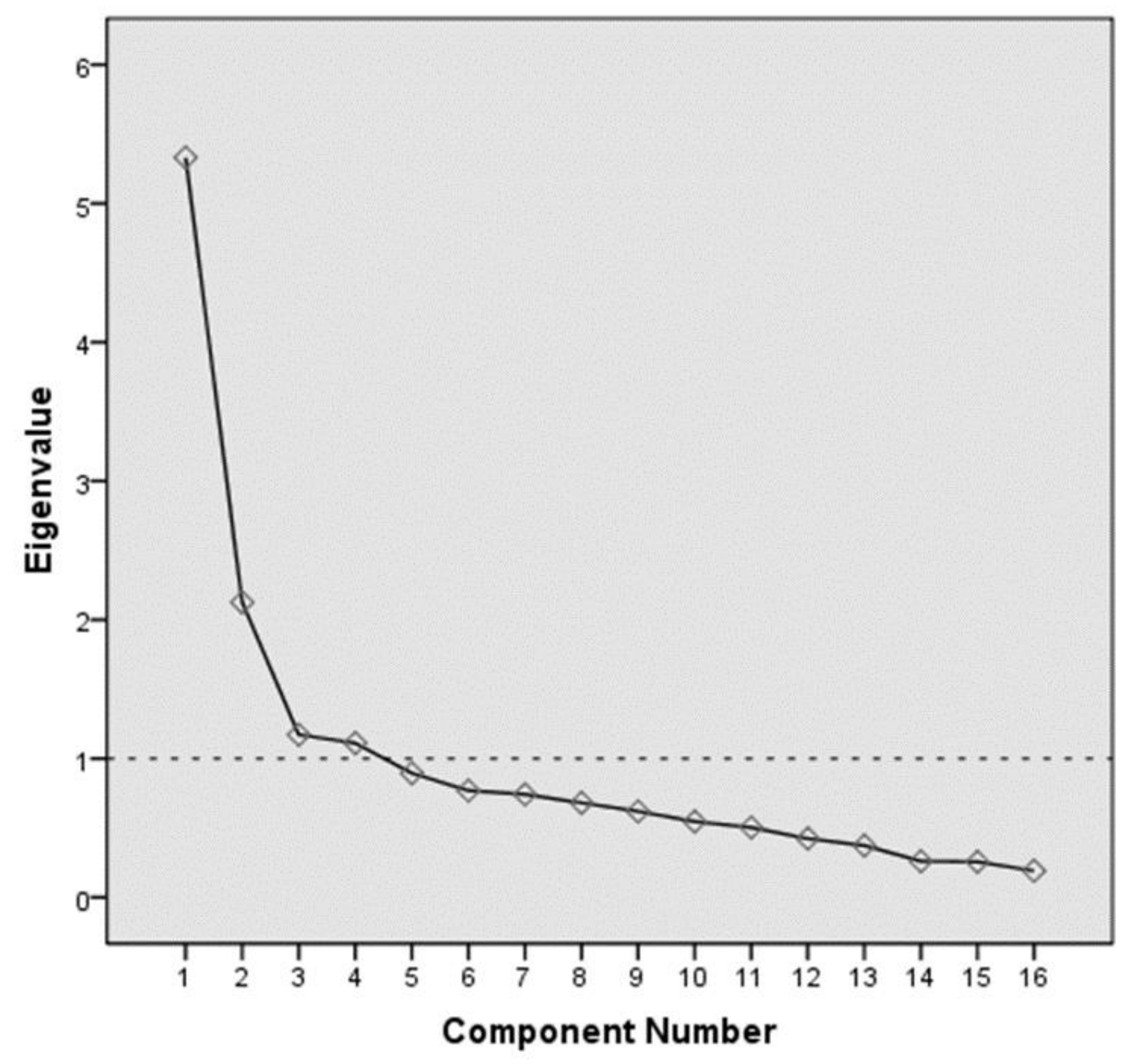

Figure 1. Parallel analysis (scree plot) for determining the number of the factors 
medRxiv preprint doi: https://doi.org/10.1101/2021.01.16.21249923; this version posted January 20, 2021. The copyright holder for this preprint (which was not certified by peer review) is the author/funder, who has granted medRxiv a license to display the preprint in perpetuity. It is made available under a CC-BY-NC 4.0 International license .

Table 4. Factor loadings and eigenvalues from the exploratory factor analysis $(N=217)$

\begin{tabular}{|c|c|c|c|c|c|}
\hline \multirow[b]{2}{*}{ Item } & \multicolumn{4}{|c|}{ Factor components } & \multirow[b]{2}{*}{ Communality } \\
\hline & 1 & 2 & 3 & 4 & \\
\hline 2 & .778 & & & & 699 \\
\hline 5 & .745 & & & & 630 \\
\hline 6 & .761 & & & & 612 \\
\hline 7 & .635 & & & & .714 \\
\hline 8 & .750 & & & & .622 \\
\hline 9 & .758 & & & & .624 \\
\hline 13 & .668 & & & & .664 \\
\hline 3 & & .786 & & & 670 \\
\hline 17 & & .626 & & & .509 \\
\hline 19 & & .656 & & & .511 \\
\hline 20 & & .623 & & & .474 \\
\hline 12 & & & .494 & & .439 \\
\hline 15 & & & .816 & & .696 \\
\hline 16 & & & .793 & & 683 \\
\hline 7 & & & & .530 & .714 \\
\hline 14 & & & & .649 & .495 \\
\hline 18 & & & & .758 & 698 \\
\hline Eigenvalue & 5.331 & 2.126 & 1.171 & 1.111 & \\
\hline Explanation variation (\%) & 33.318 & 13.286 & 7.321 & 6.947 & \\
\hline Accumulated variation $(\%)$ & 33.318 & 46.605 & 53.926 & 60.872 & \\
\hline
\end{tabular}

